\title{
In-Situ Stress Estimation by Back Analysis Based on Wellbore Deformation with Consideration of Pore Pressure
}

\author{
Cui Lin* and D.H. Steve Zou \\ Department of Civil and Resource Engineering, Dalhousie University, Halifax, Nova Scotia, Canada
}

\begin{abstract}
In oil and gas industry, wellbore stability control is paramount in an operation. It is essential to have information of the in situ stresses in well planning and prevention of wellbore failure. However, the current available measurement methods for in situ stresses in petroleum engineering are costly and often give scattering results. In this paper, a more practical displacement-based back analysis technique is proposed to determine the magnitude and orientation of the in situ stresses. The purpose is to provide an alternative tool for small operators in petroleum industry. An analytical solution is derived from displacement-stress relationship around a well in an isotropic rock with consideration of pore pressure. This method can be applied to calculate the displacement at any point around the well induced by drilling. In a reversed order, it can be used to calculate the in situ stresses from measured displacements at a number of locations on the borehole wall. For practical purpose, drained and undrained constitutive 2D models using measured diametrical deformation at different locations around a borehole wall as the input data have been developed to estimate the in situ stresses. Program codes in Matlab were written to facilitate the analysis under different conditions. An example is introduced to test the model and the program. The results validated this back-analysis approach and made a reliable estimation of the in situ stresses. The effects of pore pressure are also evaluated and are found to have significant impact on the shape of wellbore deformation. This impact differs for the drained and undrained conditions.
\end{abstract}

Keywords: in situ stresses, wellbore, back-analysis, diametrical deformation, constitutive model

\section{Introduction}

Underground formations are always in a stressed state due to the stresses in the ground, known as the in situ stresses resulted from the weight of the overlaying strata and the locked-in stresses of tectonic origin. Wells drilled into the rock mass are the only accesses developed to reach an oil and gas reservoir. The stability of a well is paramount to an operation. In situ stresses refer to the static stresses before drilling. Together with the pore pressure in the reservoir, they are among the key factors that affect the wellbore stability and play significant roles in well planning, drilling, wellbore stability control and hydraulic-fracturing application.
Therefore getting reliable data of in situ stresses, particularly in the plane perpendicular to the well axis, is essential for the development of an oil and gas reservoir (Fjaer 2008, Sinha et al 2008, Kang et al 2009, Afsari et al 2010). At present, a number of methods are available for measuring or estimating the orientation and magnitude of the in situ stresses in petroleum engineering (Aadnøy and Looyeh 2011, Nauroy 2011). The stress state at a given point in the rock formation prior to drilling is generally presented in terms of the principal components: the vertical stress $\sigma_{v}$, the maximum horizontal stress $\sigma_{\text {hmax }}$ and minimum horizontal stress $\sigma_{h m i n}$. Normally the vertical stress can be obtained from rock density and depth.

*Corresponding Author: Cui Lin, Email: CZ789851@dal.ca, Tel: +1 (902) 494-6203

(C) Copyright 2016 Canamaple Academia Services, http://press.camdemia.ca

DOI: 10.15273/ijge.2016.01.002 
Regarding the magnitude of the maximum horizontal stress, there is no straightforward measurement method. The minimum stress magnitude can be measured using methods of hydraulic fracturing, leak-off, extended leak-off and mini-frac tests (Boonen and McElhinney 2002, Labat et al 2002, Sugiura 2009). Caliper logging systems recording the borehole shape can help detect breakouts and drilling-induced fractures, which correspond to the directions of the minimum and maximum horizontal stresses, respectively. However, the above measurement methods are costly and not affordable for small companies. In addition, the results are often influenced by local defects, accordingly less reliable

Back analysis is a practical engineering tool to evaluate geomechanical parameters of underground structures based on field measurements of some key parameters, such as displacements, strains and stresses and to optimize designs (Ledesma et al 1996a \& b, Tang and Kung 2009, Yazdani et al 2012). This method has been applied over the last few decades to predict the in situ stress state and the mechanical properties surrounding rock masses in geotechnical and mining engineering. A back analysis procedure was introduced to identify elastic parameters and earth pressure in a tunnel lining by Gioda and Maier (1980). Back analysis using measured displacement of unlined and lined tunnels through a finite element formulation was performed by Sakurai and Takeuchi (1983) to determine the initial stresses. Zou and Kaiser (1990) developed a stress change fitting technique for in situ stress determination based on back-analysis principle. In 1995, Zou (1995) presented a back-analysis inverse method using relative and convergence displacements and boundary element method to estimate the effective field rock properties and in situ stresses. Other works included Kaiser et al (1990), Sakurai (1997), Mello Franco et al (2002), Sakurai et al (2003), Jeon and Yang (2004), Oreste (2005), Miranda et al (2011) and Moreira et al (2013). Those works however did not consider pore pressure, which is an important factor in the petroleum engineering.

When a well is drilled into a formation, the stressed solid material is removed and the drilling fluid provides temporary support to the well wall.
As the fluid pressure generally does not match the in situ stresses, drilling induces stress redistribution around the well, causing a new set of stresses in the rock formation around the well. As a result, deformation (or displacement) of the rock mass around the well can be observed. In comparison to direct measurement of stresses, the displacement of a well due to stress changes can be measured more easily and reliably. Measurement of displacement is also more practical in the field. Results of stresses derived from field measurements are more representative in the vicinity for a planned well.

Due to these advantages, back-analysis of measured displacements has become a popular technique in many areas. It can be basically divided into two categories: inverse and direct approaches (Zou and Kaiser 1990, Zou 1995, Feng et al 2000, Deng and Lee 2001, Shang et al 2002, Zhang et al 2006b, Ghorbani and Sharifzadeh 2009, Deng et al 2010, Dehghan et al 2012, Moreira et al 2013). For the inverse approach, mathematical formulation is just the reverse of ordinary stress analysis. It is more efficient than the direct approach, but is not appropriate for non-linear problems. For the direct approach, the model does not need to be modified like the inverse approach and can be applied to non-linear problems. It however demands more iterations in analysis for a solution to converge.

Displacement-based back analysis makes it possible to determine the magnitude and orientation of the in situ stresses based on measurement of the diametrical deformation at different locations on a well wall induced by drilling. Measurement can be performed by a mechanical multi-arm or multi-finger caliper tool. It uses displacement sensors, which produce varying electrical signals as a result of the variation in borehole diameter. A number of measurement fingers pushing against the borehole wall are used in the tool (Maxted and Hazel 1995, MFC 2014, MSC 2014). The change in the output signals can be converted to the change in wellbore diameter using processing software. At present, commercial tools may have from 12 to 60 fingers supplied by different manufacturers such as Gowell, Hotwell, Weatherford, Sondex and Spartek systems. These tools have provided direct 
and reliable open-hole and cased-hole caliper measurements in the petroleum industry (Julian et al 2007, Warrior logging software 2014).

The indirect back-analysis technique presented below, utilizing the available borehole data from caliper log, will aid greatly in providing a simplified method to obtain the in situ stresses, particularly for small companies who cannot afford the cost of the current stress measurement technologies. However, this method has yet to be further developed with improvements to be applicable to the petroleum industry. This paper aims at developing a reliable inverse approach of back analysis method to determine the in situ stresses with consideration of pore pressure. In highly permeable rock formation (e.g., most sandstones), the permeability is sufficient to ensure that the pore fluid can flow freely, so that the pore pressure can be maintained constant. This is called a drained condition. Whereas for lowpermeable rock formation (such as shale), pore fluid cannot flow out of the pore space quickly enough, resulting in a pore pressure storage effect, an undrained condition. Two-dimensional constitutive models of the inverse problem describing the relationships between the diametrical deformation and the in situ stress are first established under drained and undrained conditions. Two program codes in Matlab were written to facilitate the analysis. This method is then validated with an example.

\section{Constitutive Model for Back Analysis Based on Diametrical Deformation of a Well with Consideration of Pore Pressure}

\subsection{Basic principle}

In general, the state of stress at a point in a rock mass can be represented by six independent components, $\sigma_{x}, \sigma_{y}, \sigma_{z}, \tau_{x y}, \tau_{y z}$ and $\tau_{z x}$. For a vertical well parallel to the $\mathrm{z}$ axis, the length to cross section dimension ratio is very high and deformation is limited to the $x-y$ plane except at the collar and the bottom. This situation is considered as a plane strain problem, with $\varepsilon_{z}=0$. In this case, the strain state can be reduced to four components corresponding to the four stress components $\sigma_{x}, \sigma_{y}$, $\sigma_{z}$ and $\tau_{x y}$, respectively, which define completely the stress state in the plane perpendicular to the well axis. Thus, stress analysis can be conducted using a two-dimensional model. The well is modeled as a hole in the ground formation, as shown in Figure 1, with an inner radius $a$. The outer boundary is considered infinite. The location of A point in the rock mass is represented by the radial distance, $r$, from the center of the hole and an angle $\theta$.

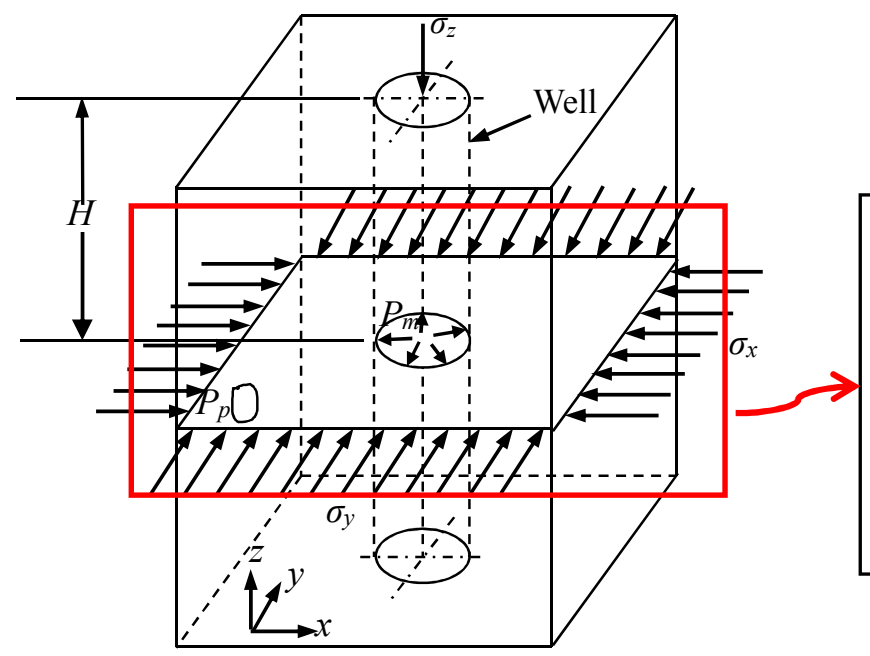

Three-dimensional model

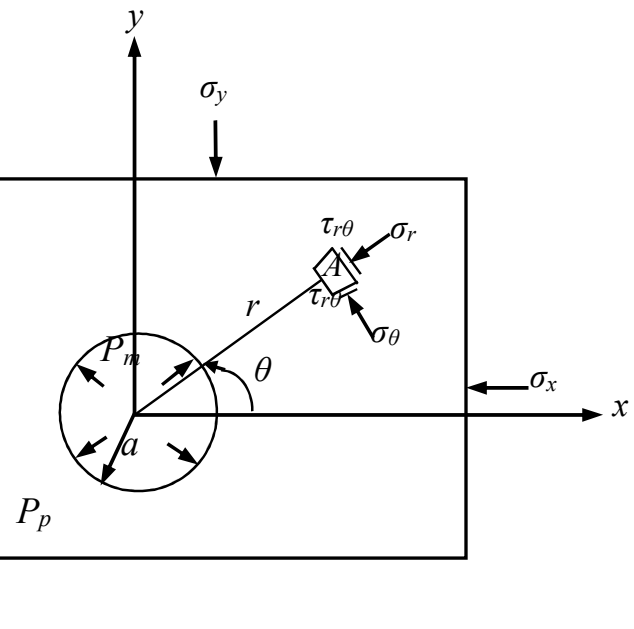

Two-dimensional model

Figure 1 Stress model surrounding a well 
Subsurface rocks are porous media saturated with fluids (e.g., water, oil, etc). Pore pressure, $P_{p}$, exists owing to the presence of formation fluids in the rock pores. Inside the borehole, there is drilling fluid with a pressure, $P_{m}$, which helps keep the well stable.

It can be observed from Figure 1 that the displacement at point $\mathrm{A}$ induced by nearby drilling consists of the normal and tangential components $u_{r}$ and $u_{\theta}$, which can also be expressed as the components $u_{x}$ and $u_{y}$ in the $x, y$ directions, respectively. The displacement is a function of the following parameters:

- the in situ stresses $\left\{\sigma_{x}, \sigma_{y}, \sigma_{z}, \tau_{x y}\right\}$ or the in situ principal stresses $\left\{\sigma_{\text {hmax }}, \sigma_{\text {hmin }}, \sigma_{z}, \beta\right\}$

- the geometry of the well being drilled (radius $\left.r_{o}\right)$

- the distance from the well $(r)$

- the properties of the rock mass (Young's modulus $E$, Poisson's ratio $v$, Biot's constant $\alpha$, seepage coefficient $\delta$, porosity $\varphi$, Skempton's coefficient $s$ )

- the mud pressure $P_{m}$ and the pore pressure $P_{p}$.

In this study, the linear elastic model and the following assumptions are applied:

- Rock formation is homogeneous.

- Rock formation is isotropic (this means that the mechanical properties, such as Young's modulus and Poisson's ratio are considered to be scalar).

According to the displacement-stress relationship, deformation of a circular hole in an isotropic linear elastic rock formation can be described in a matrix form as a function of the in situ stress components, drilling fluid pressure and pore pressure (Zhang et al 2006b)

$$
u=M \sigma-M_{m} P_{m}-M_{p} P_{p}
$$

where $u=\left\{u_{r}, u_{\theta}\right\}$ is a displacement vector in cylindrical system, $\sigma=\left\{\sigma_{x}, \sigma_{y}, \tau_{x y}\right\}$ is a vector of the initial state of stress,

$\mathrm{M}$ is the coefficient matrix of size $(2 \times 3)$, depending on the location, rock properties and well size, $M_{m}$ and $M_{p}$ are the coefficient matrices of size $(2 \times 1)$, varying with rock properties and well size.
The difference in well diameter between the drilled and the measured by caliper logging devices represents the convergence between two opposite points on the well wall induced by drilling, as depicted in Figure 2.

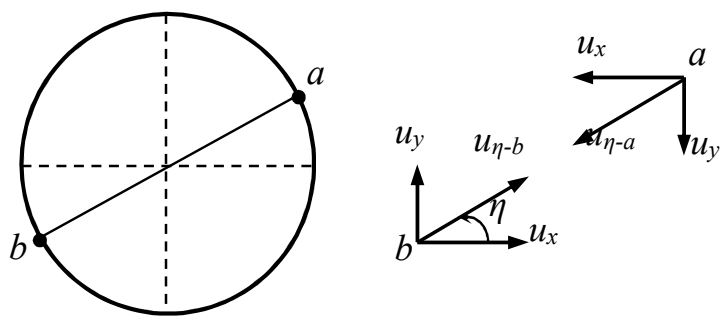

Figure 2 Convergence between two opposite points on the well wall

The diametrical deformation is the sum of the radial displacement components at the two opposite points on the wall along the measurement line (Zou 1995).

$$
u_{c o n}=u_{\eta-a}+u_{\eta-b}
$$

where $u_{\eta-a}$ is the radial displacement component along $\eta$ direction at point $a$ and $u_{\eta-b}$ at point $b . \eta$ is the angle between the measurement line and horizontal direction. At any point

$$
u_{\eta}=T_{\eta} u_{g}
$$

where $T_{\eta}=[\cos \eta, \sin \eta]$ and $u_{g}=\left\{u_{x}, u_{y}\right\}$.

The displacement $u_{g}$ can be obtained from $u$ in cylindrical system by coordinate transformation.

$$
u_{g}=T u
$$

where $T$ is the transformation matrix related to the angle $\theta$ with respect to $x$ axis (two-dimensional model in Figure 1).

Substituting Eqns. (1), (3) and (4) into Eqn. (2) gives

$$
u_{c o n}=c_{1} M_{c o n} \sigma-c_{2} M_{\text {conm }} P_{m}-c_{3} M_{\text {conp }} P_{p}
$$

where $c_{1}, c_{2}$ and $c_{3}$ are constants, which are relevant to $r_{o}, E, v, \alpha, \varphi$ and $\delta . M_{c o n,}, M_{c o n m}$ and $M_{\text {conp }}$ are the coefficient matrices of convergence which are dependent on the coordinates of two opposite points on the borehole wall along the measurement line or the measurement angle, borehole geometry and rock properties. 


$$
\begin{aligned}
& M_{\text {con }}=\left(T_{\eta} T M\right)_{a}+\left(T_{\eta} T M\right)_{b} \\
& M_{\text {conm }}=\left(T_{\eta} T M_{m}\right)_{a}+\left(T_{\eta} T M_{m}\right)_{b} \\
& M_{\text {conp }}=\left(T_{\eta} T M_{p}\right)_{a}+\left(T_{\eta} T M_{p}\right)_{b}
\end{aligned}
$$

The diametrical deformation in any direction on the borehole wall due to drilling can now be calculated from Eqn. (5) if the in situ stresses are known.

On the other hand, if a number of measurements are made in different directions, Eqn. (5) gives a set of equations. If the rows of $M_{\text {con }}$ are linearly independent, the matrix $\left(M_{c o n}{ }^{T}\right) M_{c o n}$ is invertible. In this case Eqn. (5) has only one optimum solution for the stress from least square method and it is given by

$$
\hat{\sigma}=\left(M_{c o n}{ }^{*}\right)^{-1}\left(M_{c o n}{ }^{T}\right)\left(1 / c_{1}\right) u_{c o n}{ }^{*}
$$

where $M_{c o n}{ }^{*}=M_{c o n}{ }^{T} M_{c o n}$ and $u_{c o n}{ }^{*}=u_{c o n}+$ $c_{2} M_{\text {conm }} P_{m}+c_{3} M_{\text {conp }} P_{p}$. The superscript " $T$ " and "1 " denote matrix transpose and inversion, respectively.

Thus, in a reversed order, the in situ stresses can be determined uniquely from the measured diametrical deformations in the field in different directions around the borehole wall. It is noted that the number of the measurements $n$ should be greater than the number of unknown parameters (e.g. $n>3$ in two-dimensional model).

\subsection{Stresses around a well with pore pressure}

The near-wellbore stresses under plane strain condition can be obtained based on the linear elastic model, which can be decomposed into four parts, as shown in Figure 3.

1) The stresses induced by the in situ stresses

$$
\left\{\begin{array}{l}
\sigma_{r}=m_{1}\left(1-\frac{r_{o}^{2}}{r^{2}}\right)+m_{2}\left(1-4 \frac{r_{o}^{2}}{r^{2}}+3 \frac{r_{o}^{4}}{r^{4}}\right) \\
\sigma_{\theta}=m_{1}\left(1+\frac{r_{o}^{2}}{r^{2}}\right)-m_{2}\left(1+3 \frac{r_{o}^{4}}{r^{4}}\right) \\
\sigma_{z z}=\sigma_{z}-4 v m_{2} \frac{r_{o}^{2}}{r^{2}} \\
\tau_{r \theta}=m_{3}\left(1+2 \frac{r_{o}^{2}}{r^{2}}-3 \frac{r_{o}^{4}}{r^{4}}\right)
\end{array}\right.
$$

where $m_{1}=\frac{1}{2}\left(\sigma_{x}+\sigma_{y}\right)$,
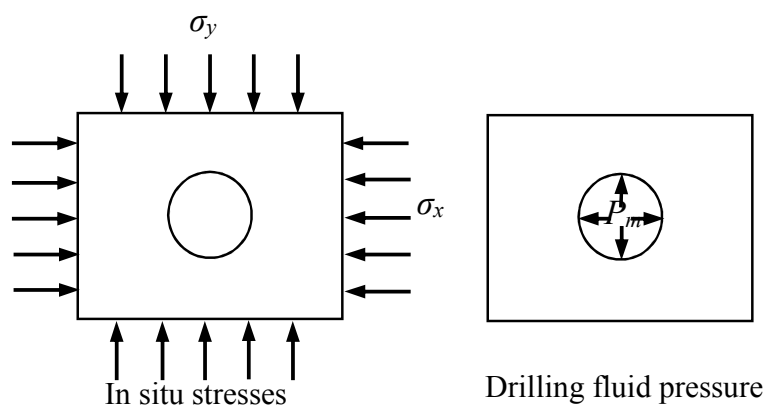

Drilling fluid pressure

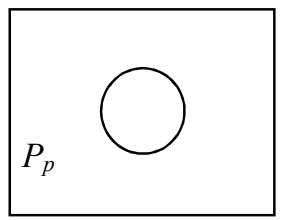

Pore pressure

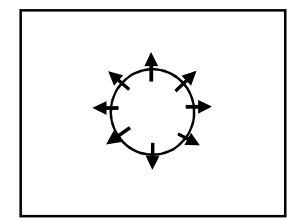

Seepage effect pressure
Figure 3 Stress composition around a wellbore

$$
\begin{aligned}
& m_{2}=\frac{1}{2}\left(\sigma_{x}-\sigma_{y}\right) \cos 2 \theta+\tau_{x y} \sin 2 \theta, \text { and } \\
& m_{3}=-\frac{1}{2}\left(\sigma_{x}-\sigma_{y}\right) \sin 2 \theta+\tau_{x y} \cos 2 \theta
\end{aligned}
$$

2) The stresses induced by drilling fluid pressure

$$
\left\{\begin{array}{l}
\sigma_{r}=P_{m} \frac{r_{o}^{2}}{r^{2}} \\
\sigma_{\theta}=-P_{m} \frac{r_{o}^{2}}{r^{2}}
\end{array}\right.
$$

3) The stresses induced by pore pressure

Pore pressure is vital in any rock mechanics study of porous, fluid-filled rock systems. The pore fluid will carry part of the total stresses applied to the system, thus relieve the rock matrix from part of the load.

Under drained condition, the pore pressure can be maintained to be constant in the domain under consideration. The effective stress as defined by Terzaghi is equal to the total stress minus the pore pressure (Zhang et al 2006a).

$$
\left\{\begin{array}{l}
\sigma_{r}=-\alpha P_{p} \\
\sigma_{\theta}=-\alpha P_{p} \\
\sigma_{z}=-\alpha P_{p}
\end{array}\right.
$$

For undrained situation, the pore pressure is instantaneously modified with respect to its original homogeneous value, which can be 
calculated by Skempton's equation (Charlez 1997).

$$
\Delta P_{p}=s \Delta \sigma
$$

where $s$ is the Skempton's coefficient and Ä $o$ is the variation in mean stress; and

$$
\begin{aligned}
& s=\frac{1}{\alpha}\left[1-\frac{K_{B}}{K_{u}}\right] \\
& \Delta \sigma=-\frac{4\left(1+v_{u}\right)}{3} m_{3} \frac{r_{o}{ }^{2}}{r^{2}}
\end{aligned}
$$

$K_{B}, K_{u}$ and $v_{u}$ are respectively drained bulk modulus, undrained bulk modulus, and undrained Poisson's ratio.

Hence, the stress from pore pressure is

$$
\sigma=-\alpha\left[P_{p}+\frac{4\left(1+v_{u}\right) s}{3} m_{3} \frac{r_{o}{ }^{2}}{r^{2}}\right]
$$

Eqn. (14) indicates that pore pressure varies with the radial position and the azimuth after drilling under undrained condition.

4) The superimposed stresses induced by the seepage effect of drilling fluid

During drilling, the drilling fluid pressure in general is higher than the formation pressure in permeable rock formation, so that some drilling liquid may seep into the formation under the pressure difference. Low permeable mud cake can be generated on the borehole wall for drilling fluid with good performance. There are two effects. One is to consolidate the wall and prevent it from caving-in, and the other is to keep drilling fluid from flowing into the formation. However, when the performance of drilling fluid is not good, a part of fluid in the well also penetrates into the formation. All these cause the loss of the drilling fluid. The rock formation is assumed to be a porous medium and Darcy's law is applied for fluid flow in this medium, the superimposed stresses surrounding the borehole induced by radial flow of drilling fluid into the pore space in the formation can be expressed as (Zhao 2007):

$$
\left\{\begin{array}{l}
\sigma_{r}=\delta\left[\frac{\alpha(1-2 v)}{2(1-v)}\left(1-\frac{r_{o}^{2}}{r^{2}}\right)-\varphi\right]\left(P_{m}-P_{p}\right) \\
\sigma_{\theta}=\delta\left[\frac{\alpha(1-2 v)}{2(1-v)}\left(1+\frac{r_{o}{ }^{2}}{r^{2}}\right)-\varphi\right]\left(P_{m}-P_{p}\right)
\end{array}\right.
$$

By combining Eqns. (8), (9), (10) or (14), (15) together, the effective stresses components under drained and undrained conditions can be described by Eqn. (16) and (17), respectively.

For drained condition

$$
\{\sigma\}=\left[M_{c c}\right]\left\{\sigma_{0}\right\}-\left[M_{c c m}\right] P_{m}-\left[M_{c c p}\right] P_{p}
$$

For undrained condition

$$
\left\{\sigma_{u}\right\}=\left[M_{c c}\right]\left\{\sigma_{0}\right\}-\left[M_{c c u m}\right] P_{m}-\left[M_{c c u p}\right] P_{p}
$$

where $\left\{\sigma_{0}\right\}=\left\{\sigma_{x}, \sigma_{y}, \sigma_{z}, \tau_{x y}\right\}$,

$$
\begin{aligned}
& \{\sigma\}=\left\{\sigma_{x}, \sigma_{y}, \sigma_{z}, \tau_{x y}\right\}_{\text {drained }} \text {, and } \\
& \left\{\sigma_{u}\right\}=\left\{\sigma_{x}, \sigma_{y}, \sigma_{z}, \tau_{x y}\right\}_{\text {undrained }}
\end{aligned}
$$

$\left[M_{c c}\right]$ is the transformation coefficient matrix from Cartesian coordinate system to cylindrical coordinate system. $\left[M_{c c m}\right]$ and $\left[M_{c c u m}\right]$ represent the coefficient matrices correlated with mud pressure. $\left[M_{c c p}\right]$ and $\left[M_{\text {ccup }}\right]$ represent the coefficient matrices correlated with pore pressure.

\subsection{Relationship between displacement at a point on the borehole wall and the in situ stresses}

Following Hooke's law, the relation between the strains and stresses for plane strain condition $\left(\sigma_{z}=\right.$ $\left.v\left(\sigma_{x}+\sigma_{y}\right)\right)$ can be written as

$\left\{\begin{array}{l}\frac{E}{1-v^{2}} \varepsilon_{x}=\sigma_{x}-\frac{v}{1-v} \sigma_{y} \\ \frac{E}{1-v^{2}} \varepsilon_{y}=\sigma_{y}-\frac{v}{1-v} \sigma_{x}\end{array}\right.$

The corresponding relations between the strains and stresses in cylindrical coordinate:

$$
\left\{\begin{array}{l}
\frac{E}{1-v^{2}} \varepsilon_{r}=\sigma_{r}-\frac{v}{1-v} \sigma_{\theta} \\
\frac{E}{1-v^{2}} \varepsilon_{\theta}=\sigma_{\theta}-\frac{v}{1-v} \sigma_{r}
\end{array}\right.
$$

From the physical and geometrical law, we have displacement-strain relations

$$
\left\{\begin{array}{l}
\varepsilon_{r}=\frac{\partial u_{r}}{\partial r} \\
\varepsilon_{\theta}=\frac{1}{r} \frac{\partial u_{\theta}}{\partial \theta}+\frac{u_{r}}{r}
\end{array}\right.
$$

Therefore 


$$
\left\{\begin{array}{l}
\frac{\partial u_{r}}{\partial r}=\frac{1-v^{2}}{E} \sigma_{r}-\frac{v(1+v)}{E} \sigma_{\theta} \\
\frac{\partial u_{\theta}}{\partial \theta}=r\left[\frac{1-v^{2}}{E} \sigma_{\theta}-\frac{v(1+v)}{E} \sigma_{r}\right]-u_{r}
\end{array}\right.
$$

The displacement in the radial \& tangential direction at a point on the borehole wall with $r=a$ under drained and undrained conditions can be obtained by inserting Eqns. (16) and (17) into Eqn. (21) and integrating:

$$
\left\{\begin{array}{l}
u_{r} \\
u_{\theta}
\end{array}\right\}=c_{4} r_{o} M_{u}\left\{\begin{array}{l}
\sigma_{x} \\
\sigma_{y} \\
\tau_{x y}
\end{array}\right\}-M_{m} P_{m}-M_{p} P_{p}
$$

where

$$
\begin{aligned}
& M_{u}=\left[\begin{array}{ccc}
1+2 \cos \theta & 1-2 \cos 2 \theta & 4 \sin 2 \theta \\
-2 \sin 2 \theta & 2 \sin 2 \theta & 4 \cos 2 \theta
\end{array}\right], \text { and } \\
& c_{4}=\frac{1-v^{2}}{E} .
\end{aligned}
$$

2.4 Relation between convergence of two opposite points on the borehole wall and the in situ stresses

Figure 4 illustrates the convergence calculation model. $\theta_{i_{-} 11}$ and $\theta_{i_{-} 12}$ are the measurement angles of two opposite points $a$ and $b ;\left(x_{i_{-}} 11, y_{i_{-} 11}\right)$ and $\left(x_{i_{-}} 12, y_{i_{-} 12}\right)$ are the coordinates of points $a$ and $b$.

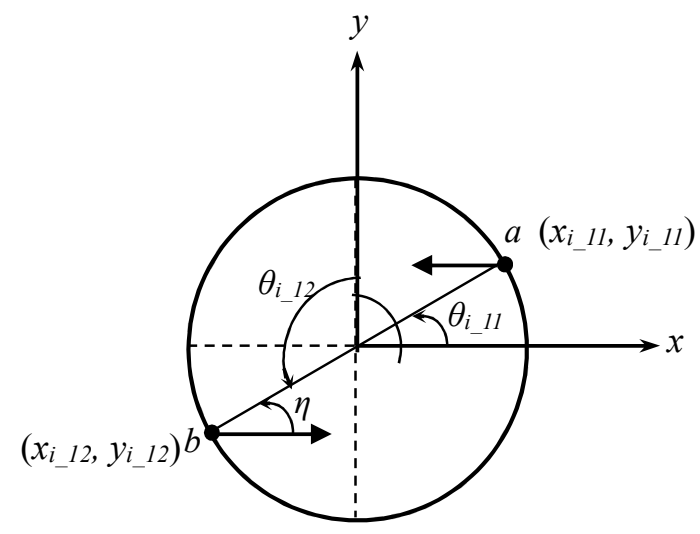

Figure 4 Convergence calculation model

The convergence for points $a$ and $b$

$$
u_{\text {coni }}=M_{\text {coni }} \sigma-M_{\text {conmi }} P_{m}-M_{\text {conpi }} P_{p}
$$

where $M_{\text {coni }}, M_{\text {conmi }}$ and $M_{\text {conpi }}$ are the coefficient matrices associated with $r_{o}, E, v, \alpha, \varphi$, and $\delta$, the measurement angle $\theta_{i_{-}} 11$ and $\theta_{i_{-} 12}$ or the coordinates of two opposite points $\left(x_{i_{-}} 11, y_{i_{-}} 11\right)$ and $\left(x_{i_{-}} 12, y_{i_{-}} 12\right)$.

\subsection{Formulation for determining the in situ stresses by using diametrical deformation}

For $n$ measured diametrical deformation, it is convenient to express Eqn. (23) in matrix form. Let

$$
\begin{gathered}
u_{\text {conn }}=\left\{\begin{array}{c}
u_{\text {con } 1} \\
u_{\text {con } 2} \\
\vdots \\
u_{\text {conn }}
\end{array}\right\}, \quad M_{\text {conn }}=\left[\begin{array}{ccc}
M_{1_{-} 1} & M_{1_{-} 2} & M_{1_{-3} 3} \\
M_{2-1} & M_{2 \_} & M_{2 \_} 3 \\
\vdots & \vdots & \vdots \\
M_{n_{-} 1} & M_{n_{-} 2} & M_{n_{-} 3}
\end{array}\right] \\
M_{\text {conmn }}=\left[\begin{array}{c}
M_{m 1} \\
M_{m 2} \\
\vdots \\
M_{m n}
\end{array}\right], \quad M_{\text {conpn }}=\left[\begin{array}{c}
M_{p 1} \\
M_{p 2} \\
\vdots \\
M_{p n}
\end{array}\right]
\end{gathered}
$$

We can rewrite Eqn. (23) as

$$
u_{\text {conn }}=M_{\text {conn }} \sigma-M_{\text {conmn }} P_{m}-M_{\text {conpn }} P_{p}
$$

Eqn. (25) is a set of linear equations with three unknown parameters. If the number of measurement is more than three, it becomes a set of redundant equations. If the least square method is adopted in Eqn. (25), the unknown parameters can be solved, such that the in situ stresses appear as outputs and the measured convergence quantities as inputs as follows:

$$
\hat{\sigma}=\left(M_{\text {conn }}{ }^{*}\right)^{-1}\left(M_{\text {conn }}{ }^{T}\right) u_{\text {conn }}{ }^{*}(26)
$$

where $M_{\text {conn }}{ }^{*}=M_{\text {conn }}{ }^{T} M_{\text {conn }}$ and

$u_{\text {conn }}{ }^{*}=u_{\text {conn }}+M_{\text {conmn }} P_{m}+M_{\text {conpn }} P_{p}$.

\subsection{Computer programming}

Matlab is employed to write two program codes to facilitate the calculation of the in situ stresses through displacement-based back-analysis based on drained and undrained constitutive models.

The input data for back analysis are the geometry of borehole, the angles or coordinates of measurement locations, the diameter changes caused by drilling at different locations, pore pressure, mud pressure, the properties of rock mass including Young's modulus, drained and undrained Poisson's ratio, Biot's constant, seepage coefficient, porosity, and Skempton's coefficient. The output data is a quantitative description of the in situ stresses $\left\{\sigma_{x}, \sigma_{y}, \tau_{x y}\right\}$ or $\left\{\sigma_{h \max }, \sigma_{h \min }, \varphi\right\}$. Figure 5 shows the program interface. 


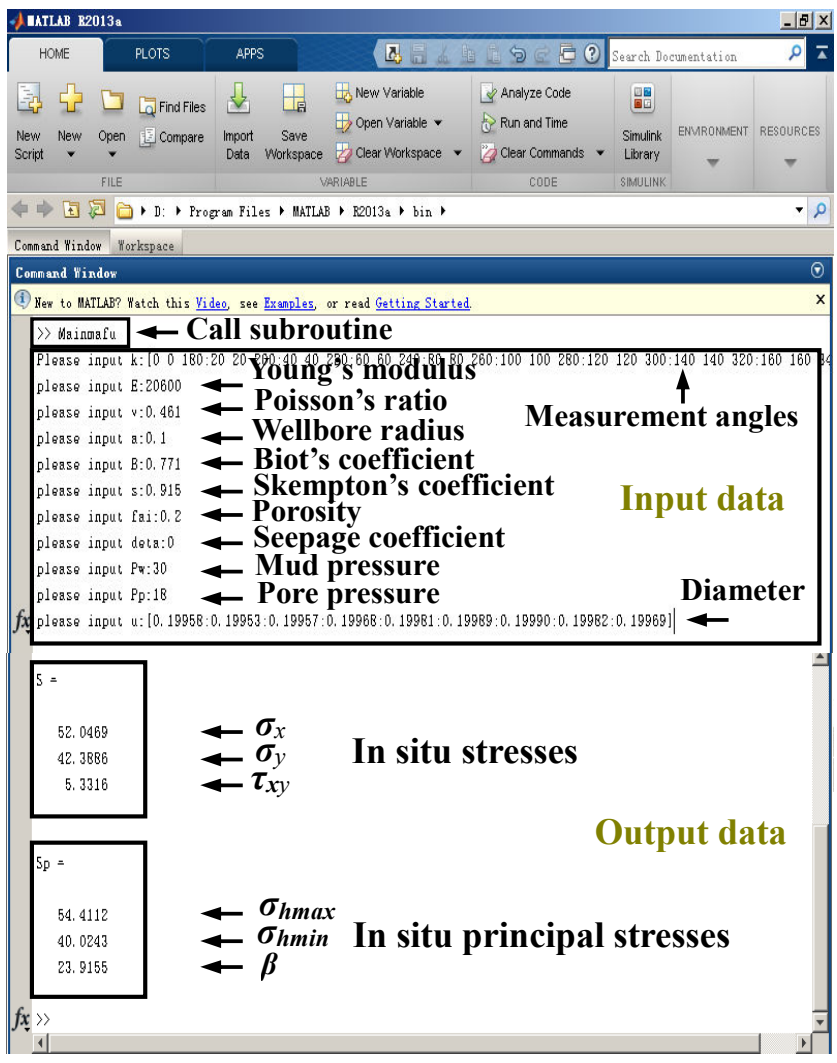

Figure 5 Program interface

\section{Validation}

An example of a circular well is introduced to demonstrate the procedure of this back-analysis technique and to test the constitutive model and the program. Analysis is performed under the assumption of linear elastic behavior of rock mass and a two dimensional stress field in the plane perpendicular to the well. The in situ stresses are assumed to be $\sigma_{h \max }=54.5 \mathrm{MPa}$ and $\sigma_{h \min }=40 \mathrm{MPa}$ (at a depth of $2000 \mathrm{~m}$ ). The formation properties are (from Zhang et al 2006a, Tao and Ghassemi 2010): elastic modulus $E=20.6 \mathrm{GPa}$; drained Poisson's ratio $v=0.189$ and undrained Poisson's ratio $v_{u}=0.461$; Biot's coefficient $\alpha=$ 0.771 ; porosity $\varphi=20 \%$. The radius of the well is $0.1 \mathrm{~m}$. A total of 9 measurements of diameter are supposed to be made at different locations around the borehole (Figure 6). Table 1 lists the measurement angles of the 9 measurements. Four cases are considered: Case 1, rock formation with no pore pressure and no mud pressure. Case 2, rock formation with mud pressure and no pore pressure.
Case 3, high-permeable rock formation with pore and mud pressure. Case 4 low-permeable rock formation with pore and mud pressure, as shown in Table 2.

Data of exact diametrical deformation caused by drilling at the 9 measurement locations are generated using Eqn. (25) with assumed in situ stresses. These data are deemed as measurement convergence, which are applied to determine the in situ stresses by the established back analysis model of Eqn. (28). Then random errors of up to $\pm 15 \%$ are introduced to the exact diametrical deformation data to produce the hypothetical data (Table 3). Furthermore, the back-analyzed in situ stresses are used to calculate the diametrical deformation at those locations for comparison.

The calculation procedures in different scenarios are carried out using the program written in Matlab. The applied and back-analyzed stress results are displayed in Table 4 . The solutions of the in situ stresses are quite similar to the actual ones when the measured diametrical deformation is exact. There are very small differences between these two sets of stress data. When up to $15 \%$ errors are added to the diametrical deformation data, the solutions are slightly changed. The differences are less than the introduced errors of $15 \%$. The corresponding diametrical deformations calculated from applied stresses and backanalyzed stresses at 9 measurement locations are shown in Figure 7.

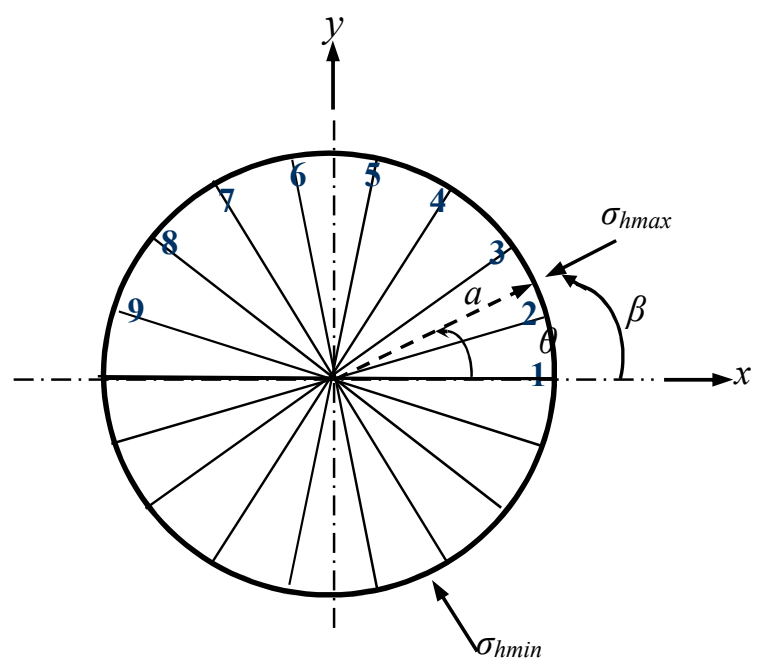

Figure 6 Diameter measurements at different locations around the wellbore 
Table 1 Measurement angles and coordinates of the 9 measurement locations

\begin{tabular}{cccccccccc}
\hline Location & 1 & 2 & 3 & 4 & 5 & 6 & 7 & 8 & 9 \\
\hline$\beta_{i}\left(^{\circ}\right)$ & 0 & 20 & 40 & 60 & 80 & 100 & 120 & 140 & 160 \\
\hline$\theta_{i \_11}\left({ }^{\circ}\right)$ & 0 & 20 & 40 & 60 & 80 & 100 & 120 & 140 & 160 \\
\hline$\theta_{i \_12}\left({ }^{\circ}\right)$ & 180 & 200 & 220 & 240 & 260 & 280 & 300 & 320 & 340 \\
\hline
\end{tabular}

Table 2 Parameters for different cases

\begin{tabular}{cccccccccc}
\hline \multirow{2}{*}{ Parameters } & \multicolumn{7}{c}{ Rock mass properties } & $P_{m}$ & $P_{p}$ \\
& \cline { 2 - 9 }$(\mathrm{GPa})$ & $v$ & $v_{u}$ & $S$ & $\alpha$ & $\varphi(\%)$ & $\delta$ & $(\mathrm{MPa})$ & $(\mathrm{MPa})$ \\
\hline Case 1 & 20.6 & 0.189 & - & - & 0.771 & 0 & 0 & 0 & 0 \\
\hline Case 2 & 20.6 & 0.189 & - & - & 0.771 & 0 & 0 & 30 & 0 \\
\hline Case 3 & 20.6 & 0.189 & - & - & 0.771 & 20 & 1 & 30 & 18 \\
\hline Case 4 & 20.6 & - & 0.461 & 0.915 & 0.771 & 20 & 0 & 30 & 18 \\
\hline
\end{tabular}

Table 3 Diametrical deformation data

\begin{tabular}{|c|c|c|c|c|c|c|c|c|c|c|}
\hline \multicolumn{2}{|c|}{ Diametrical deformation (mm) } & 1 & 2 & 3 & 4 & 5 & 6 & 7 & 8 & $\overline{9}$ \\
\hline \multirow{3}{*}{$\begin{array}{c}\text { Case } 1 \\
P_{p}=0 \mathrm{MPa}, \\
P_{m}=0 \mathrm{MPa}\end{array}$} & Exact & 1.10 & 1.20 & 1.10 & 0.97 & 0.78 & 0.64 & 0.62 & 0.72 & 0.89 \\
\hline & Errors (\%) & -8 & 5 & 6 & -7 & 10 & 15 & -15 & 12 & -9 \\
\hline & Hypot & 1.01 & 1.26 & 1.17 & 0.90 & 0.86 & 0.74 & 0.53 & 0.80 & 0.81 \\
\hline \multirow{3}{*}{$\begin{array}{c}\text { Case } 2 \\
P_{p}=0 \mathrm{MPa}, \\
P_{m}=30 \mathrm{MPa}\end{array}$} & Exact & 0.84 & 0.93 & 0.89 & 0.75 & 0.56 & 0.42 & 0.40 & 0.49 & 0.67 \\
\hline & Errors $(\%$ & 9 & -7 & 10 & -15 & 15 & 11 & -6 & 8 & -5 \\
\hline & Hypot & 0.92 & 0.87 & 0.98 & 0.63 & 0.64 & 0.47 & 0.37 & 0.53 & 0.64 \\
\hline \multirow{3}{*}{$\begin{array}{c}\text { Case } 3 \text { Drained } \\
P_{p}=18 \mathrm{MPa} \\
P_{m}=30 \mathrm{MPa}\end{array}$} & $\mathrm{ct}$ & 0.67 & 0.76 & 0.72 & 0.57 & 0.39 & 0.25 & 0.22 & 0.32 & 0.50 \\
\hline & Errors $(\%$ & -10 & 8 & 5 & 12 & -15 & -7 & 15 & -6 & 10 \\
\hline & Hypothet & 0.60 & 0.82 & 0.75 & 0.64 & 0.33 & 0.23 & 0.26 & 0.30 & 0.55 \\
\hline \multirow{3}{*}{$\begin{array}{c}\text { Case } 4 \text { Undrained } \\
P_{p}=18 \mathrm{MPa} \\
P_{m}=30 \mathrm{MPa}\end{array}$} & Exact & 0.42 & 0.47 & 0.43 & 0.32 & 0.19 & 0.11 & 0.10 & 0.18 & 0.31 \\
\hline & Errors (\%) & 10 & 8 & -7 & 15 & -6 & 12 & -15 & 5 & -9 \\
\hline & Hypothetic & 0.46 & 0.51 & 0.40 & 0.37 & 0.18 & 0.12 & 0.09 & 0.19 & 0.28 \\
\hline
\end{tabular}

Table 4 Applied and back-analyzed in situ stresses

\begin{tabular}{clccc}
\hline & In situ stresses (MPa) & $\sigma_{\operatorname{hmax}}$ & $\sigma_{\text {hmin }}$ & $\beta\left({ }^{\circ}\right)$ \\
\hline & Applied stresses & 54.50 & 40.00 & 24.00 \\
\hline Case 1 & Back-analyzed stresses with exact $u_{c o n}$ & 55.22 & 40.05 & 23.12 \\
\cline { 2 - 5 }$P_{p}=0 \mathrm{MPa}, P_{m}=0 \mathrm{MPa}$ & Back-analyzed stresses with hypothetic $u_{c o n}$ & 55.35 & 40.62 & 27.19 \\
\hline Case 2 & Back-analyzed stresses with exact $u_{c o n}$ & 54.50 & 40.00 & 24.00 \\
\cline { 2 - 5 }$P_{p}=0 \mathrm{MPa}, P_{m}=30 \mathrm{MPa}$ & Back-analyzed stresses with hypothetic $u_{c o n}$ & 54.82 & 40.88 & 24.01 \\
\hline Case 3 Drained & Back-analyzed stresses with exact $u_{c o n}$ & 54.58 & 40.02 & 24.03 \\
\cline { 2 - 5 }$P_{p}=18 \mathrm{MPa}, P_{m}=30 \mathrm{MPa}$ & Back-analyzed stresses with hypothetic $u_{c o n}$ & 55.50 & 40.06 & 24.44 \\
\hline Case 4 Undrained & Back-analyzed stresses with exact $u_{c o n}$ & 54.41 & 40.02 & 23.92 \\
\cline { 2 - 5 }$P_{p}=18 \mathrm{MPa}, P_{m}=30 \mathrm{MPa}$ & Back-analyzed stresses with hypothetic $u_{c o n}$ & 55.40 & 40.05 & 24.60 \\
\hline
\end{tabular}



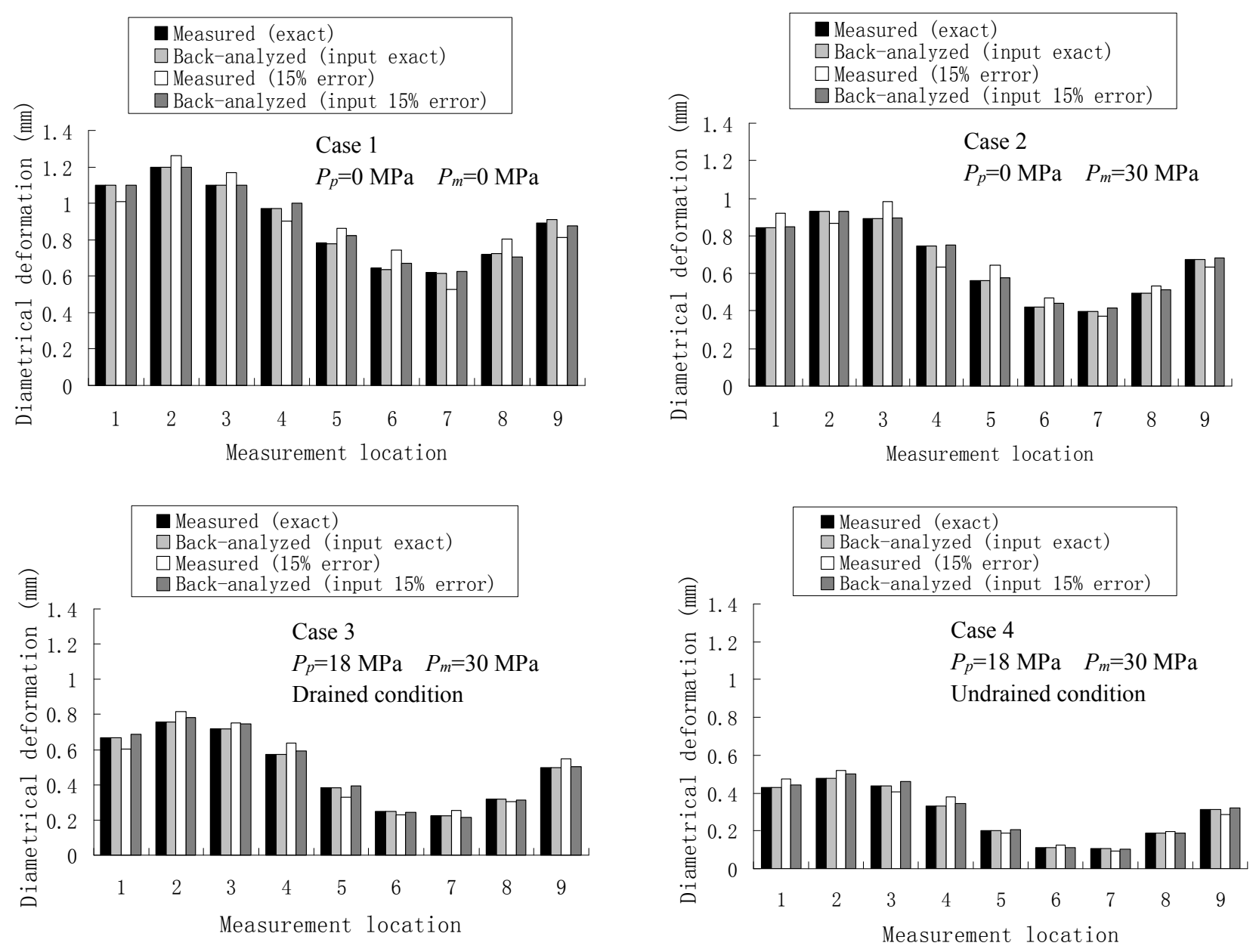

Figure 7 Comparison of diametrical deformation from applied and back-analyzed stresses

Comparing these values, it can be found that there is a fairly good agreement between the diametrical deformations obtained from applied and back-analyzed stresses when input data is exact. If the input data containing errors are used, the diametrical deformation obtained from backanalyzed stresses shows less error than the input data.

These results reveal the reliability of constitutive model and the validity of program and this inverse approach of back analysis taking into account pore and mud pressure.

\section{Effects of Pore Pressure and Mud Pressure on Borehole Deformation}

Pore pressure is an important factor for controlling wellbore stability. Pore pressure change and distribution can affect the redistribution of stresses around the borehole after drilling, which can be reflected by the deformation of wellbore.

Figure 8 presents near wellbore pore pressure distribution at the different measuring directions. After introduction of a borehole into an anisotropic geostatic stress field, the pore pressures of different locations keep the same under drained condition. However, under undrained condition the pore pressure depends on the azimuth. It can be seen that the pore pressure has a higher concentration in the direction of $\sigma_{\text {hmin }}$ and lower concentration in the direction of $\sigma_{\text {hmax }}$. In order to analyze the effect of pore pressure distribution on the wellbore deformation, the radial displacement (half of convergence) at different locations obtained from back-analyzed in situ stresses in the above example are depicted in Figure 9. There is a maximum displacement in the direction of $\sigma_{h \max }$ 


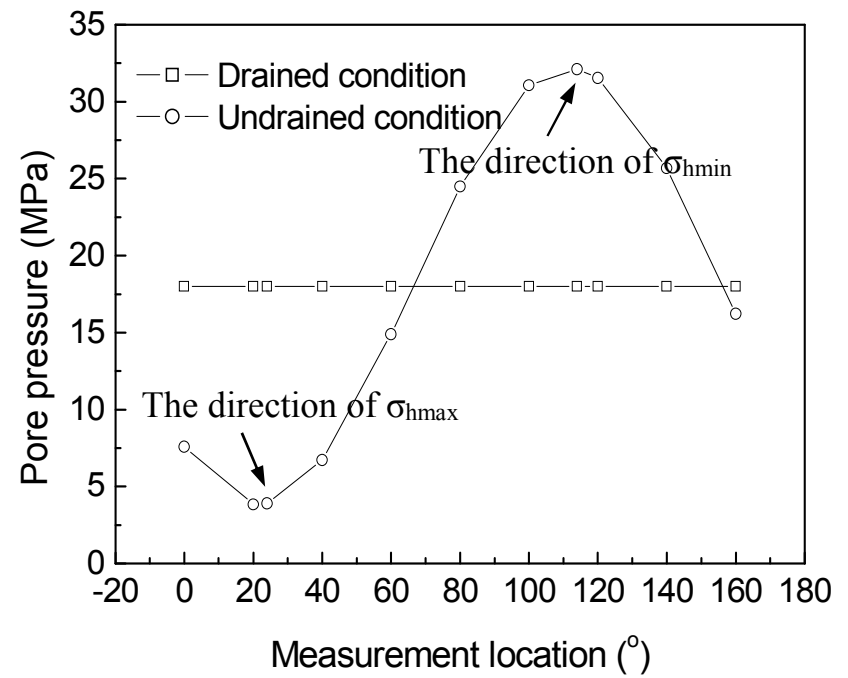

Figure 8 Pore pressure distribution at the different measuring directions after drilling

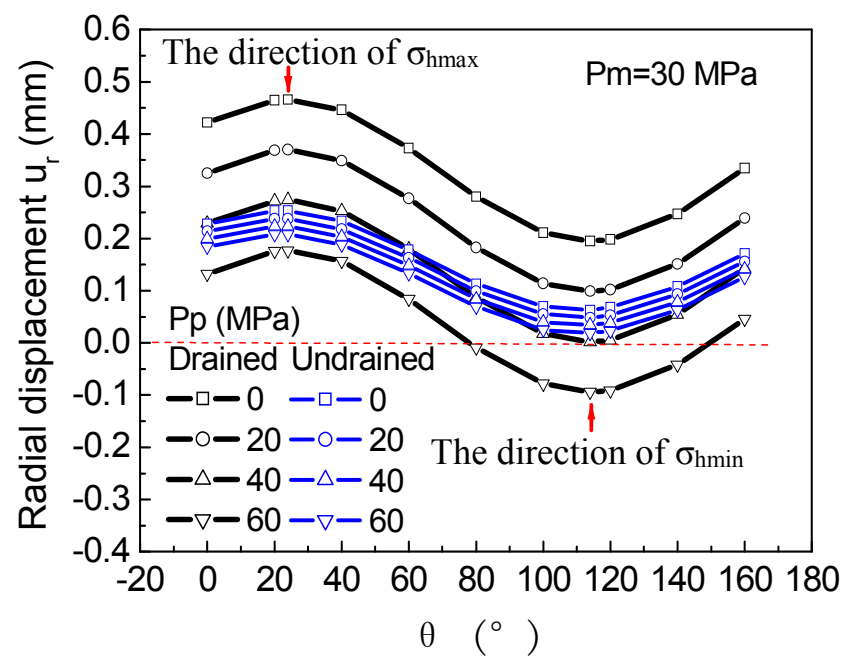

(a) different pore pressure

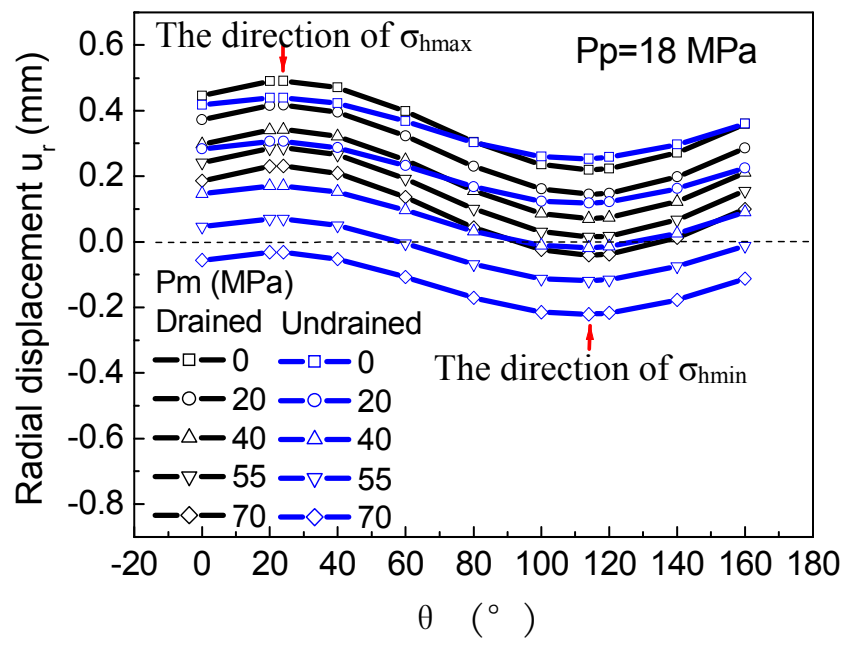

(b) different mud pressure

Figure 9 Radial deformations at different locations at the wellbore wall under drained and undrained conditions and a minimum displacement in the direction of $\sigma_{\text {hmin. }}$. The undrained results show a decrease difference in radial displacement between the direction of $\sigma_{h \min }$ and $\sigma_{h \max }$ contrary to drained condition. This phenomenon induces different wellbore shapes after drilling under these two conditions. The wellbore profiles plotted using enlarged displacements (40 times of the actual value) are given in Figure 10. The geometry of wellbore is changed from circle to oval in both conditions. The ovalisation is a result of anisotropic geostatic stresses, which have a possible impact on wellbore stability. Undrained effect can decelerate well convergence in the direction of $\sigma_{\text {hmax }}$ and its ovalisation in the perpendicular direction. In this study, due to pore pressure distribution differs for drained and undrained conditions, two different back analysis models have been established, which can be selected on the basis of the type of rock formation. From the Eqns. (18), (19) and (24), the increase in pore pressure magnitude will reduce stresses and displacement at the borehole wall. This indicates the stresses applied on the rocks in the nearwellbore region are partially supported by the pore pressure. For each increase of $20 \mathrm{MPa}$ of the pore pressure, the reduced values of drained and undrained radial displacements are about $0.1 \mathrm{~mm}$ and $0.015 \mathrm{~mm}$, respectively (Figure 9a). The changes in radial displacements as a result of the same pore pressure change show obvious difference for drained and undrained conditions.

The mud pressure will also cause deviation in radial displacement. Figure $9 \mathrm{~b}$ shows the radial displacement at the mud pressure of $0,20,40,55$ and $70 \mathrm{MPa}$. However, in the field, for a given depth, the mud pressure is limited in a range proportional to the mud density and depth. In this example of $2000 \mathrm{~m}$ depth, $P_{m}$ may not reach 70 MPa but at deeper location, this may take place. The main borehole failure mechanisms include fracturing (tensile failure) and collapse (compressive failure). Based on the "mud weight window" - the range of mud weight that can maintain a stable borehole, compressive failures occur, possibly causing the well to collapse if the mud pressure is lower than $P_{w c}$. Mud weight can help to provide partial support to the wellbore wall. Increasing mud pressure can make the wellbore 
wall move away from the center and reduce the risk of wellbore collapse, as implied by the displacement shown in Figure 9b. This is the same as the pore pressure. But for the influence of mud pressure change on drained and undrained conditions, it is unlike the pore pressure effect. The reduced value of drained radial displacement is relatively close to that of the undrained radial displacement. At high mud pressure, expansion occurs along the axis corresponding to $\sigma_{h m i n}$ (Figure 10b). When the mud pressure exceeds $P_{w f}$, tensile failure takes place in the direction of $\sigma_{\text {hmax }}$.

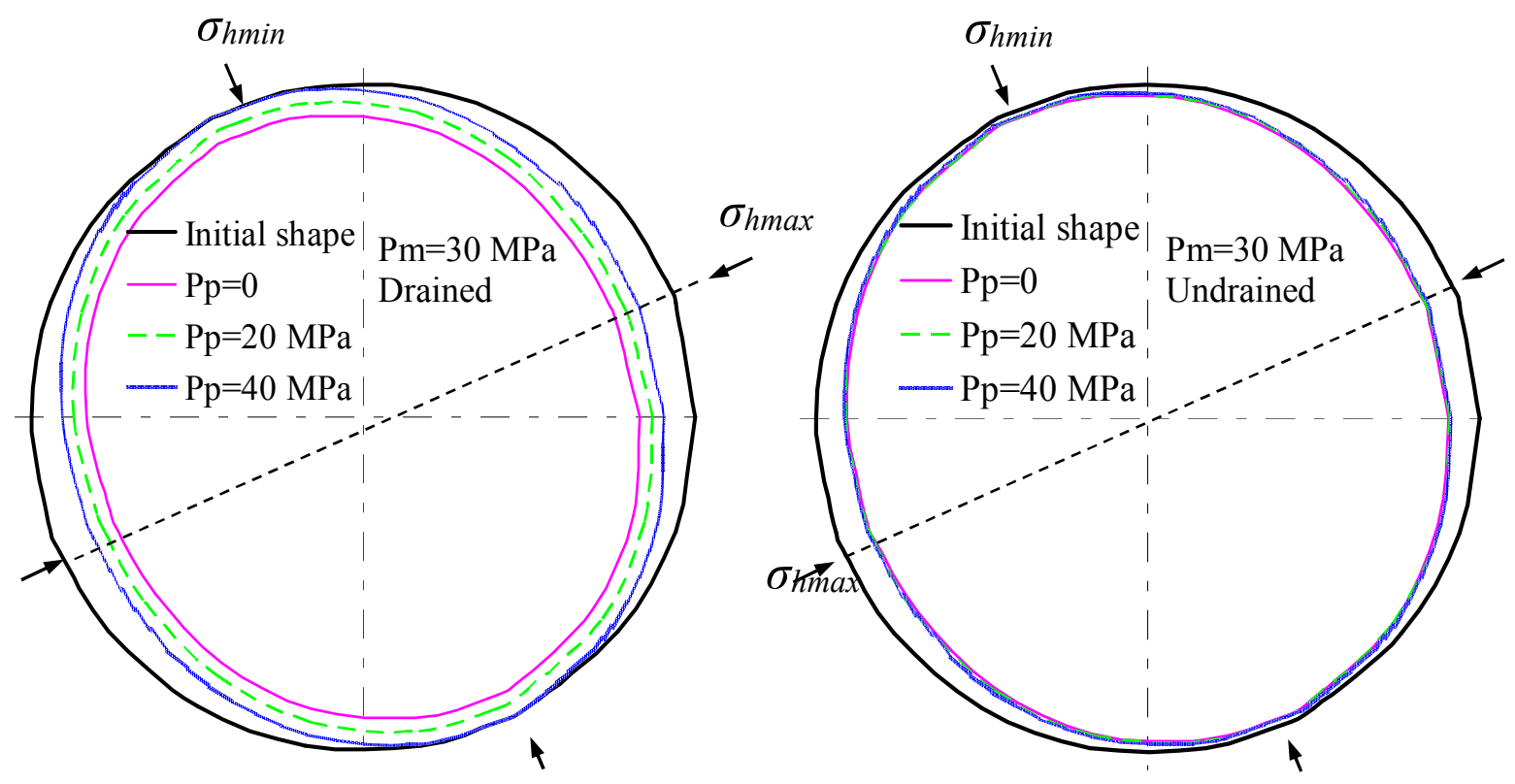

a) Effect of pore pressure

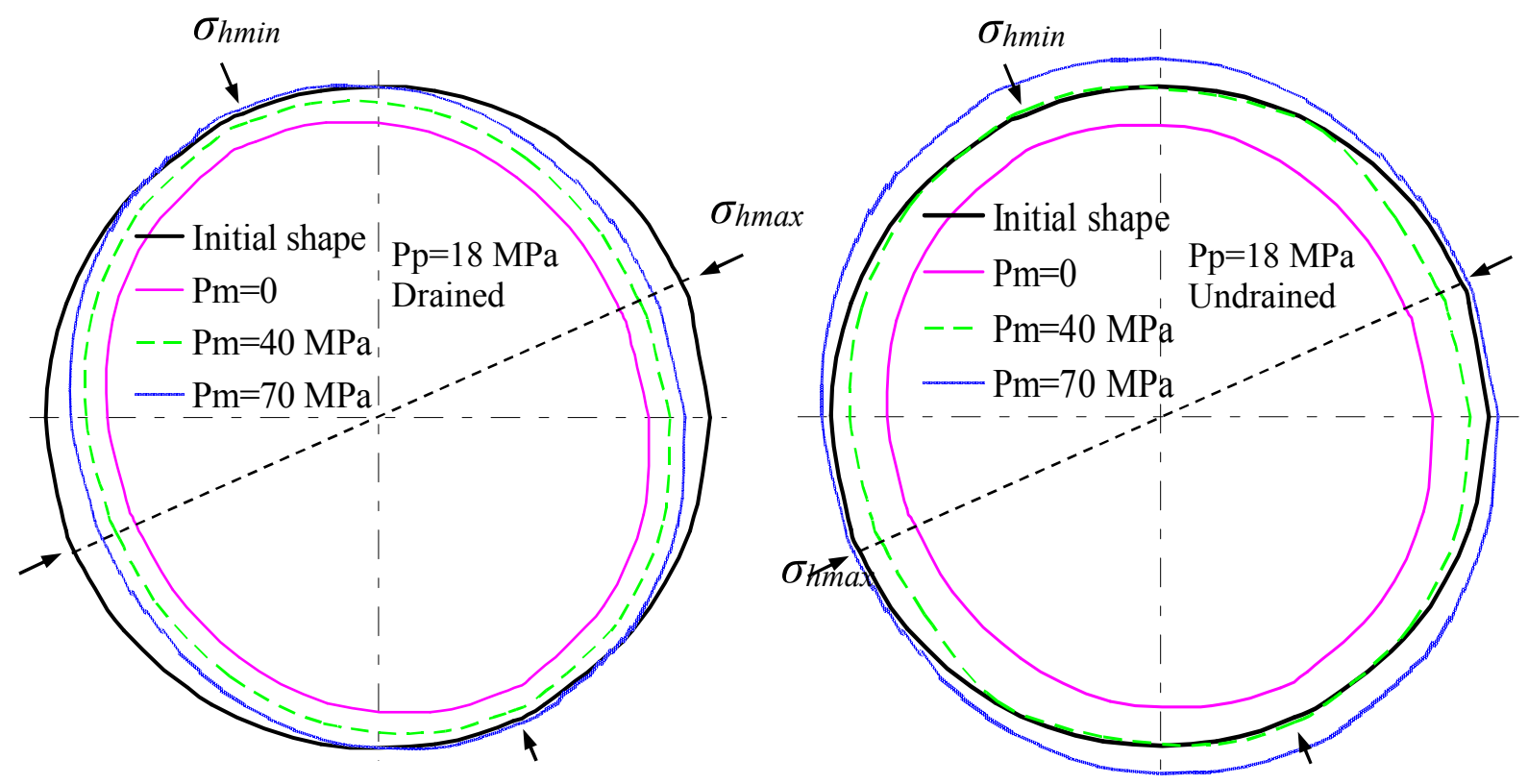

b) Effect of mud pressure

Figure 10 Wellbore shapes under drained and undrained conditions. Note: all displacement values are enlarged by 40 times to show the effect 
Failure criteria can be applied to estimate the minimum mud pressure $\left(P_{m c}\right)$ and the maximum mud pressures $\left(P_{m f}\right)$, beyond which the wellbore will fail, if the in-situ stress and pore pressure are known. Therefore the determination of the critical pressure for maintaining wellbore stability is highly dependent on the in situ stress field, the formation pore pressure and rock properties. The back analysis method in this study can be further used to get the proper mud weight and analyze the wellbore stability.

The above discussion of the effects of pore pressure and mud pressure on wellbore deformation clearly demonstrates the importance of the pore pressure when developing back analysis models and studying wellbore stability for different types of rock formation. There are other factors, such as thermal effect, which may play a role in wellbore stability as well and need to be explored in future work. Meanwhile, field data need to be used to evaluate the applicability of the proposed method.

\section{Conclusions}

A simplified inverse approach of back analysis technique has been developed, which provides an alternative and practical method for estimating in situ stresses around a drilled well. The technique is based on measurement of convergence, or diametrical changes on the wall of the well in different directions induced by drilling. The field pore pressure has also been taken into consideration. Constitutive 2D models corresponding to drained and undrained conditions, respectively, allow estimation of the in situ stresses under different pore pressure distribution. These models can be further used to determine proper mud weight and analyze the wellbore stability for different type of rock formation.

The method is tested with an example, which demonstrates the accuracy and reliability of the results. The back-analyzed in situ stresses with this method are very close to the applied stresses. Furthermore, this method allows evaluation of the effect of pore pressure and mud pressure on wellbore deformation and demonstrates the change of well shape under drained and undrained conditions.

\section{References}

Aadnøy, B.S. and R. Looyeh, 2011. Petroleum Rock Mechanics: Drilling Operations and Well Design. Amsterdam, Oxford: Gulf Professional Pub.

Afsari, M., M. Amani, S.M. Razmgir, H. Karimi and S. Yousefi, 2010. Using drilling and logging data for developing $1 \mathrm{~d}$ mechanical earth model for a mature oil field to predict and mitigate wellbore stability challenges. Paper SPE 132187 presented at the CPS/SPE International Oil \& Gas Conference and Exhibition. Beijing, China, 8 - 10 June.

Boonen, P. and G. McElhinney, 2002. Rock mechanics and wellbore stability analysis while drilling using LWD sonic, density and caliper measurements. Paper SPE/ISRM 78208 presented at the SPE/ISRM Rock Mechanics Conference. Irving, Texas, USA, 20 - 23 October.

Charlez, Ph. A., 1997. Rock Mechanics, volume 2: Petroleum Applications. Paris: Editions Technip.

Dehghan, A.N., S.M. Shafiee and F. Rezaei, 2012. 3-D stability analysis and design of the primary support of Karaj metro Tunnel: based on convergence data and back analysis algorithm. Engineering Geology, 141-142: 141 - 149.

Deng, J.H. and C.F. Lee, 2001. Displacement back analysis for a steep slope at the Three Gorges Project site. International Journal of Rock Mechanics and Mining Sciences, 38(2): 259 268.

Deng, X.H., W.S. Xu and J.Y. Cao, 2010. Inversion analysis of mechanical parameters of surrounding rocks in buried-deep tunnel. Journal of Computational Information Systems, 6(6): 1877 - 1886.

Feng, X.T., Z.Q. Zhang and Q. Sheng, 2000. Estimating mechanical rock mass parameters relating to the Three Gorges Project permanent shiplock using an intelligent displacement back analysis method. International Journal of Rock Mechanics and Mining Sciences, 37(7): 1039 - 1054.

Fjaer, E., 2008. Petroleum Related Rock Mechanics, Amsterdam, London: Elsevier.

Ghorbani, M. and M. Sharifzadeh, 2009. Long 
term stability assessment of Siah Bisheh powerhouse cavern based on displacement back analysis method. Tunnelling and Underground Space Technology, 24(5): 574 583.

Gioda, G. and G. Maier, 1980. Direct search solution of an inverse problem in elastoplasticity: identification of cohesion, friction angle and in situ stress by pressure tunnel tests. International Journal for Numerical Methods in Engineering, 15(12): $1823-1848$

Jeon, Y.S. and H.S. Yang, 2004. Development of a back analysis algorithm using flac. International Journal of Rock Mechanics and Mining Sciences, 41(3): 441 - 442.

Julian, J.Y., D.A. Cismoski, R.O. Younger, J.P. Burton and M.W. Lawrence, 2007. Use of 3D visualization software for multifinger caliper analysis at Prudhoe Bay, Alaska. Paper SPE 106625 presented at the 2007 SPE/ICoTA Coiled Tubing and Well Intervention Conference and Exhibition. Woodlands, Texas, USA, 20 - 21 March.

Kaiser, P.K., D.H. Zou and P.A. Lang, 1990. Stress determination by back analysis of excavationinduced stress changes - a case study. Rock Mechanics and Rock Engineering, 23(3): 185 200.

Kang, Y.F., M.J. Yu, S. Miska and N.E. Takach, 2009. Wellbore Stability: a critical review and introduction to dem. Paper SPE 124669 presented at the SPE Annual Technical Conference and Exhibition. New Orleans, Louisiana, USA, 4 - 7 October.

Labat, C., S. Brady, M. Everett, D. Ellis, M. Doghmi, J.C. Tomlinson and G. Shehab, 2002. 3D azimuthal LWD caliper. Paper SPE 77526 presented at the SPE Annual Technical Conference and Exhibition. San Antonio, Texas, USA, 29 September - 2 October.

Ledesma, A., A. Gens and E.E. Alonso, 1996a. Parameter and variance estimation in geotechnical back analysis using prior information. International Journal for Numerical and analytical methods in Geomechanics, 20(2): 119 - 141.

Ledesma, A., A. Gens and E.E. Alonso, 1996b. Estimation of parameters in geotechnical back analysis - I. Maximum likelihood approach. Computers and Geotechnics, 18(1): 1 - 27.

Maxted, I. and P. Hazel, 1995. Advances in multifinger caliper technology and data acquisition. Paper OTC 7871 presented at the $27^{\text {th }}$ Annual Offshore Technology Conference. Houston, Texas, USA, 1 - 4 May.

Mello Franco, J.A., J.L. Armelin, J.A.F. Santiago, J.C.F. Telles and W.J. Mansur, 2002. Determination of the natural stress state in a Brazilian rock mass by back analysis excavation measurements: a case study. International Journal of Rock Mechanics \& Mining Sciences, 39(8): 1005 - 1032.

MFC, 2014. Multi-finger Caliper Guide. Gowell Petroleum Equipment Company.

Miranda, T., D. Dias, S. Eclaircy-Caudron, A.G Correia and L. Costa, 2011. Back analysis of geomechanical parameters by optimisation of a 3D model of an underground structure. Tunnelling and Underground Space Technology, 26(6): 659 - 673.

Moreira, N., T. Miranda, M. Pinheiro, P. Fernandes, D. Dias, L. Costa and J. Sean-Cruz, 2013. Back analysis of geomechanical parameters in underground works using an evolution strategy algorithm. Tunnelling and Underground Space Technology, 33: 143 - 158.

MSC, 2014. High Resolution 40- and 60- arm Multi-Sensor Caliper Tool Guide. Weatherford. Nauroy, J.F., 2011. Geomechanics Applied to the Petroleum Industry, Paris: Editions Technip.

Oreste, P., 2005. Back-analysis techniques for the improvement of the understanding of rock in underground constructions. Tunnelling and Underground Space Technology, 20(1): 7 - 21.

Sakurai, S., 1997. Lessons learned from field measurements in tunnelling. Tunnelling and Underground Space Technology, 12(4): 453 460.

Sakurai, S. and K. Takeuchi, 1983. Back analysis of measured displacement of tunnels. Rock Mechanics and Rock Engineering, 16: 173 180.

Sakurai, S., S. Akutagawa, K. Takeuchi, M. Shinji, and N. Shimizu, 2003. Back analysis for tunnel engineering as a modern observational method. Tunnelling and Underground Space Technology, 18(2-3): 185 - 196. 
Shang, Y.J., J.G. Cai, W.D. Hao, X.Y. Wu and S.H. $\mathrm{Li}$, 2002. Intelligent back analysis of displacements using precedent type analysis for tunneling. Tunnelling and Underground Space Technology, 17(4): 381 - 389.

Sinha, B.K., J. Wang, S. Kisra, J. Li, V. Pistre, T. Bratton, M. Sanders and C. Jun, 2008. Estimation of formation stresses using borehole sonic data. Paper SPWLA 2008F presented at the SPWLA $49^{\text {th }}$ Annual Logging Symposium. Edinburgh, Scotland, 25 - 28 May. Sugiura, J., 2009. Novel mechanical caliper image while drilling and borehole image analysis. SPWLA 50th Annual Logging Symposium. Houston, Texas, USA, 21 - 24 June.

Tang, Y.G. and G.T.C. Kung, 2009. Application of nonlinear optimization technique to back analyses of deep excavation. Computers and Geotechnics, 36(1-2): 276 - 290.

Tao, Q.F. and A. Ghassemi, 2010. Porothermoelastic borehole stress analysis for determination of the in situ stress and rock strength. Geothermics, 39(3): 250 - 259.

Warrior logging software, 2014. Multi-finger Caliper and Pipe Tally Guide. Scientific Data Systems, Inc.

Yazdani, M., M. Sharifzadeh and M. Ghorbani, 2012. Displacement-based numerical back analysis for estimation of rock mass parameters in Siah Bisheh powerhouse cavern using continuum and discontinuum approach.
Tunnelling and Underground Space Technology, 28: 41 - 48.

Zhao, X.L., 2007. Study on Borehole Stability in Sidewall Rock of Petroleum Drilling. Master thesis, Chongqing University, College of Resources and Environmental Science.

Zhang, J., W.B. Standifird, K. Adesina and G. Keaney, 2006a. Wellbore stability with consideration of pore pressure and drilling fluid interactions. Paper ARMA/USRMS 06922 presented at the $41^{\text {st }}$ U.S. Symposium on Rock Mechanics (USRMS): "50 Years of Rock Mechanics - Landmarks and Future Challenges." Golden, Colorado, 17 - 21 June.

Zhang, L.Q., Z.Q. Yue, Z.F. Yang, J.X. Qi and F.C. Liu, 2006b. A displacement-based backanalysis method for rock mass modulus and horizontal in situ stress in tunneling Illustrated with a case study. Tunnelling and Underground Space Technology, 21(6): 636 649.

Zou, D.H. and P.K. Kaiser, 1990. Determination of in situ stresses from excavation-induced stress changes. Rock Mechanics and Rock Engineering, 23(3): 167 - 184.

Zou, D.H., 1995. Evaluation of field properties and stress condition by displacement back-analysis using boundary element principle. CAMI' 95 $3^{\text {rd }}$ Canadian Conference on Computer Application in the Mineral Industry. Montreal, Canada, 22 - 25 October. 